\title{
GABRIELA MISTRAL Y LA REFORMA AGRARIA CHILENA*
}

\author{
Grinor Rojo de la Rosa
}

* Proyecto FONDECYT Nº 1160019. 


\section{GRÍNOR ROJO DE LA ROSA}

Doctor en Filosofía por la Universidad de Iowa, Estados Unidos. Ensayista, crítico cultural y literario, es Profesor Titular en el Centro de Estudios Culturales Latinoamericanos de la Universidad de Chile, del que fue director hasta 2010, y en el Departamento de Literatura de la misma Universidad. Ha enseñado en diversas universidades de América Latina, Europa y Estados Unidos y es autor de numerosas publicaciones sobre temas de su especialidad. Su último libro se titula Las novelas de la dictadura y la postdictadura chilena, vols. I y II. Santiago de Chile, LOM, 2016. 


\section{GABRIELA MISTRAL Y LA REFORMA AGRARIA CHILENA}

No sé yo cuándo inicia Gabriela Mistral su batalla contra el latifundio y la servidumbre (o, dicho en chileno, el "inquilinaje"). Sé, sin embargo, que, aparte de las raíces que esa batalla tiene en su acontecer personal, durante los años que viviera en el valle de Elqui, el de sus "niñeces", y que fue además donde realizó sus primeros tanteos de maestra rural, esas raíces se vieron reforzadas por su posterior estancia de México, país en el que la Revolución había hecho y seguía profundizando la primera reforma agraria en serio que se llevó a cabo en la historia de América Latina. México, que había intentado una reforma ya en los días de la independencia, cuando tanto Miguel Hidalgo como José María Morelos ordenaron la entrega de tierra a los campesinos ${ }^{1}$, que lo intentó de nuevo a mediados del siglo XIX, con la reforma liberal de Benito Juárez, y que finalmente lo logró debido a la presión del "indio" Emiliano Zapata e incorporándose así en el artículo 27 la Constitución de 1917, fue para ella un paradigma inobviable ${ }^{2}$. Mistral no podía menos que hacerse cargo de esa reforma agraria, habiéndola visto en pleno proceso y habiendo participado en y habiendo escrito sobre lo que significaba. Como en este artículo acerca del presidente Obregón, de 1923:

La cuestión agraria no había sido en nuestros países afrontada todavía; a México le ha correspondido el duro destino de empezar. Es tremendo, aunque sea glorioso, este privilegio de comenzar sin que pueda aprovecharse del tesoro de la experiencia ajena. La única que hay en esta cuestión es la europea, y nunca nos cansaremos de decir que la experiencia de Europa rara vez sirve para la América, por tratarse de campos radicalmente diversos. Con la reforma agraria no sólo buscan los hombres de la revolución mexicana el cumplimiento de las promesas democráticas hechas al pueblo; buscan algo más: la mayor producción que es en todas partes el resultado de la división de la tierra; todavía esto no se alcanza en México, pero se alcanzará en cinco años más ${ }^{3}$.

1. Decreto de Miguel Hidalgo y Costilla, dado en Guadalajara el 5 de octubre de 1910, y Proyecto de confiscación de intereses de europeos y americanos adictos al gobierno, del 2 de noviembre de 1813, ambos en Miguel Fabila. Cinco siglos de legislación agraria en México (1493-1940). México. Procuraduría Agraria, 2005.

2. Para la historia de la reforma agraria en México, véase Rafael Sánchez Morett. Reforma agraria: del latifundio al neoliberalismo. México. Plaza y Valdés, 2003.

3. Gabriela Mistral. "El presidente Obregón y la situación de México”, publicado originalmente en El Mercurio (1º de junio de 1923) y reproducido en Escritos políticos. Jaime Quezada, ed. México y Santiago de Chile. Fondo de Cultura Económica, 1994, p. 242. 
Del mismo año son sus dos artículos acerca de "Cómo se ha hecho una escuela granja en México", donde un maestro le cuenta a Mistral el experimento siguiente:

Un día empecé a cultivar una parcela en el centro del terreno, y dije a los niños solamente que hicieran lo que yo fuera haciendo.

Ellos verificaron el reparto del suelo en pequeñas secciones y se las distribuyeron. No les di lecciones previas de agricultura, porque no creo en la enseñanza teórica, sino como cosa paralela con la práctica y a veces como posterior a ella.

Se fue poblando la tierra eriaza y fea de las pequeñas manchas verdes de hortaliza. Había que ver con qué ardor trabajaban mis pequeñitos agricultores, siempre con mi vigilancia, pero sin mi ayuda, para enardecerlos de esfuerzos. No he querido matarles la alegría ingenua de que descubran ellos, de que se sientan menudos creadores.

\section{Concluye Mistral:}

la pequeña propiedad (que ellos exigirán y que conseguirán en México), aplaca la rebeldías, da dignidad a la vida humana y hace el corazón del hombre propicio a las suavidades del espíritu. La pequeña república agraria que estos niños han creado, les irá revelando el régimen económico y los caminos por donde se busca la prosperidad de un país: no tendrán el odio de la riqueza, que sólo cuaja cuando el hombre no tiene nada que defender ni amar bajo el sol porque sea suyo ${ }^{4}$.

Un año posterior, de 1924, es "México. La cuestión agraria”, que empieza así:

La crítica extranjera más enconada contra México, gira en torno de la cuestión agraria. Las reclamaciones de Estados Unidos, España y hasta de Inglaterra, son voces irritadas porque se ha herido al latifundio; ponen en el reclamo una exageración dañina y esparcen así el que la propiedad en México no tiene ninguna garantía. De este modo se crea el recelo del capital extranjero para afluir a México y se presenta a un país constitucional, viviendo la anormalidad rusa ${ }^{5}$.

4. Gabriela Mistral. "Cómo se ha hecho una escuela granja en México", I y II. Revista de Educación Primaria, 5, 6 y y7 (1923). Reproducidos en Gabriela Mistral. Croquis mexicanos. Alfonso Calderón, ed. Santiago de Chile. Nascimento, 1979, pp. 35 y 43.

5. Gabriela Mistral. "México. La cuestión agraria”. La Nueva Democracia, 9 (1924), 3. 
En su primer regreso a Chile, en 1925, Mistral viaja al Norte Chico, en "ese horrible ferrocarril del norte" $y$, después de contemplar la feracidad del valle del Aconcagua y de pasar una muy mala noche en el tren, se encuentra a la mañana siguiente con "la provincia muerta de Coquimbo" (Ibid.). Se adentra entonces en Illapel y Combarbalá, donde la sequía, la miseria y el hambre hacen estragos. Y sabe muy bien a quiénes culpar:

Defienden algunos el latifundio con argumentos como éste: "Si se crea absolutamente la pequeña propiedad, al desaparecer el dueño de una extensión vasta de suelo, desaparece también la posibilidad de hacer cualquiera empresa agrícola en grande, los canales de riego, los tractores costosos. El menudo campesino se come lo que saca de la tierra y el capital de éste no existe". Pues, Illapel y Combarbalá son latifundio puro, y ya sabemos lo que en cien años han hecho por la tierra. La sequía ha encontrado a los campesinos sin cooperativas y $\sin$ ahorros, que no se ahorra con un salario inicuo. En otros países, las sociedades agraristas tienen siempre en caja fondos para afrontar un año, por lo menos, de malas cosechas. La falta de organización campesina es otro dato de barbarie (19).

En 1926, en una carta a Pedro Aguirre Cerda, recuerda ese viaje del año anterior:

Vi la misma esclavitud rural y, lo que parece cuento, anoté que no hay un solo partido que tenga en su programa la cuestión agraria como cosa importante en un país de latifundio medioeval?

Eso en 1925 y 1926, como digo. Un par de años después, en 1928, residiendo entonces en el sur de Francia, en Avignon, y en un artículo que envía a El Mercurio [!], estampa esta diatriba:

en Chile angustiado de suelo, mitad roca volcánica, un tercio de desierto, sin más tierra verdadera que el llano central, no puede seguir viviendo el latifundismo

6. Gabriela Mistral. "Una provincia en desgracia: Coquimbo" en Recados contando a Chile. Alfonso M. Escudero. O.S.A., ed. Santiago de Chile. Editorial del Pacífico., 1957, p. 17. Mis dos citas siguientes son del mismo texto y sólo daré el número de página entre paréntesis.

7. Gabriela Mistral. "Carta a Pedro Aguirre Cerda del 28 de diciembre de 1926”. Gabriela Mistral pensando Chile. Una tentativa contra lo imposible. Jaime Quezada, ed. Santiago de Chile. Publicaciones del Bicentenario, 2004, p. 376. 
sino como despreocupación inconcebible o como amparo deliberado de un régimen bárbaro [...] los patrones deberían poner mejor cara a las leyes agrarias que lleguen al Congreso, los patrones que forman parte del Congreso y los que quedan afuera, y que manejan opiniones de prensa y de círculos. Es la ocasión de que un país de América legisle sin anticipo de sangre, y sin urgidura caliente de revuelta, sobre el problema perversamente postergado, de la propiedad rural. Que no vengan los discursos de la Cámara y los artículos de periódico a decir en país sin información de este orden, miedecillos vestidos de derecho, defendiendo con ello intereses abusivos ${ }^{8}$.

Y siete años después, en 1933, en "Ruralidad chilena", pondrá el ojo sobre su propio valle, el de Elqui:

Una hectárea por cabeza de familia resolvería el problema económico del campesino de Elqui, si el horrible y deshonesto latifundio no estuviese devorándonos y hambreándonos, allí como a lo largo del país entero. Pero la patricita, la faja mínima de nuestro asiento, la arrollan las haciendas de los "forasteros", llamando así a los grandes propietarios rurales ausentes eternos de nuestra vida y presentes urgidores del trabajo de los campesinos. Claro está que no son aquellas las haciendas del sur, que suelen cubrir medio departamento, sino pequeños fundos y hasta a veces simples granjas. Ni en esta forma temperada, sin embargo, debería existir la propiedad grande en ese pequeño corredor de cerros, densamente poblado?

Una hectárea por cabeza de familia... No pide más la poeta. No ignora que las circunstancias, tal como ella las está constatando en el valle de Elqui, no son las peores del país en esta materia, que el latifundio de esa zona no es comparable en su extensión con los del sur, pero es latifundio como quiera que sea, que explota y hambrea al campesino. Una hectárea por cabeza de familia... Eso bastaría para la existencia austera, pero suficiente, que Mistral estima que los campesinos chilenos desean, merecen y deben tener. Un año después, en 1934, en el que pudiera ser el texto en prosa más importante que escribió sobre Chile, nos da a conocer cuál es su idea acerca de esa vida agraria. Es, como era previsible, la que ella misma

8. Gabriela Mistral. “Agrarismo en Chile”. ElMercurio (23 de septiembre de 1928), 4. Lo reproduce Jaime Quezada en Escritos políticos, 50-54.

9. Gabriela Mistral. "Ruralidad chilena" en Recados contando a Chile. Alfonso M. Escudero, O.S.A., ed. Santiago de Chile. Editorial del Pacífico, 1957, p. 112. 
había experimentado en los años de su infancia, pero recordada siempre a partir del modelo de la pequeña propiedad elquina, la que en esa tierra de sus niñeces coexistía y contrastaba con la gran propiedad:

Pequeñez, la de mi aldea de infancia, me parece a mí la de la hostia que remece y ciega al creyente con su cerco angosto y blanco. Creemos que en la región, como en la hostia, está el Todo; servimos a ese mínimo llamándolo el contenedor de todo, y esa miga del trigo anual que a otro hará sonreír o pasar rectamente, a nosotros, nos echa de rodillas.

Somos las gentes de esta zona de Elqui mineros y agricultores en el mismo tiempo. En mi valle el hombre tomaba sobre sí la mina, porque la montaña nos cerca de todos lados y no hay modo de desentenderse de ella; la mujer labraba en el valle. Antes de los feminismos de asamblea y de reformas legales, 50 años antes, nosotros hemos tenido allá en unos tajos de la Cordillera el trabajo de la mujer hecho costumbre. He visto de niña regar a las mujeres a la medianoche, en nuestras lunas claras, la viña y el huerto frutal; la he visto hacer totalmente la vendimia; he trabajado con ellas en la llamada "pela del durazno", con anterioridad a la máquina deshuesadora; he hecho sus arropes, sus uvates y sus infinitos dulces llevados de la industria familiar española ${ }^{10}$.

En 1937, en "El Valle Central de Chile" se observa en Mistral un cambio, que va a marcar sus escritos posteriores acerca del tema. Por primera vez, sus buenos deseos se superponen a la atroz realidad:

Los gobiernos últimos aceleran la creación de la pequeña propiedad, único testimonio convincente de una democracia. El Valle Central, particularmente, es el lugar mejor de esta experiencia. "Quien reparte la tierra distribuye a lo divino el sol, el agua y la dicha”, dice un viejo refrán. Al norte salitrero y minero le corresponde crearnos las marejadas bruscas de riqueza; al Valle Central le corresponde un destino clásico de riqueza evolutiva, lenta y estable ${ }^{11}$.

$¿$ Que los gobiernos chilenos de los años treinta y cuarenta estuviesen acelerando la creación de la pequeña propiedad? No era tan así, lamentablemente. Hubo algunos indicios de parte de los gobiernos radicales, es cierto, el de Pedro Aguirre Cerda sobre todo (autor él mismo de El problema agrario, un libro de 1929, y en

10. Gabriela Mistral. "Breve descripción de Chile" en Ibid., 127.

11. Gabriela Mistral. "El Valle Central de Chile" en Pensando a Chile..., 43. 
cuyo programa presidencial estaba incluida la reforma, pero que no llegaron, tal vez porque no pudieron llegar, demasiado lejos. Esos gobiernos estaban interesados en el desarrollo de una industria nacional, pero no creían o no estaban convencidos de que las condiciones políticas les iban a permitir modificar el orden de cosas existente en el campo.

Ahora bien, nosotros sabemos que los años veinte, treinta y hasta fines de los cuarenta se caracterizan en América Latina por el pujante espíritu nacionalista -aquel "nacionalismo terrícola" de que habla la poeta en los comienzos de su enjundiosa reseña sobre Chile o una loca geografía, el libro de Benjamín Subercaseaux ${ }^{12}$-, pero que un tanto contradictoriamente al mismo tiempo que informa al mundo sobre la plétora y excelencia de nuestros recursos naturales, apuesta cuanto tiene a las expectativas de éxito de un capitalismo industrial de base doméstica, con participación del Estado en el manejo del aparato productivo y financiero del país de que se trate, y en el que mágicamente acabarían por converger los intereses de la empresa privada con las demandas de justicia social. La clave de dicho modelo es una industrialización a la que se piensa factible con un mejoramiento de las tecnologías, es decir sin que el agro experimente al mismo tiempo un cambio en las relaciones de propiedad y producción. Las respuestas ideológicas a este empeño fluctúan entre el respaldo sin restricciones que le brindan las capas medias y el sector moderno de la oligarquía, un apoyo más bien suspicaz por parte del proletariado y el rechazo a veces furibundo y en otras solamente melancólico que se percibe entre los antiguos dueños de la tierra.

En ese espacio ideológico amplio es donde se instala el último de los textos de Mistral que a mí me interesa recordar en esta nota, su Poema de Chile, cuya redacción ella habría iniciado en la década del veinte, según nos lo asegura Soledad Falabella, aunque yo pienso que sólo llega a constituirse en un proyecto con un significado preciso al ponerse en contacto con el marco histórico que acabo de resumir, esto es, después de la segunda visita de la poeta a Chile, en mayo de 1938, cinco meses antes del triunfo del Frente Popular. Quien está escribiendo el Poema de Chile es una mujer que ha abandonado el territorio de su nacimiento dieciséis años antes, que en el interín ha vuelto a él sólo dos veces, pero que, a despecho de las remotas latitudes en las que ha optado por establecer residencia, se mantiene obsesivamente al tanto acerca de todo lo que acontece en el ambiente natural, político y literario que por su propia voluntad dejara atrás. ¿En qué consiste ese país que Mistral preserva en su

12. Gabriela Mistral. "Benjamín Subercaseaux y su libro 'Chile o una loca geografía”" en Gabriela piensa en... Roque Esteban Scarpa, ed. Santiago de Chile. Andrés Bello, 1978, pp. 95-108. 
memoria, cuáles son los elementos que ella escoge destacar en su Poema... y cuáles los que prefiere disminuir o ignorar?

Porque el Poema de Chile parece un poema escrito en elogio de Chile, y en cierto sentido lo es, si lo consideramos nada más que en el plano de su discurso mimético, pero apenas oculta bajo ese discurso existe ahí una dimensión crítica que no sólo discrepa con sino que se opone a la primera. El discurso inconsciente y no mimético nos dice en el Poema de Chile lo contrario de lo que dice el discurso consciente y mimético. Nos dice que lo rescatable del país chileno no son las ciudades sino el campo (“... las santiaguinas sólo/ me ven escandalizadas/ y gritan --‘iVálgame Dios!' / o me echan perros de caza". "Jardines", $87^{13}$ ) y no tanto el trabajo industrial como el agrícola. Mistral no lo terminó nunca y no hay que romperse la cabeza averiguando el por qué. Menos que un poema acerca de Chile, el Poema de Chile acaba siendo, si es que favorecemos la segunda lectura, una suerte de bitácora de la trayectoria existencial de la poeta durante los últimos veinte años de su vida, bitácora de las peripecias de su ser interior, como un sujeto precario, lacerada, dividida, rota y doliente, pero también resentida y rencorosa:

--Me han contado las comadres

que tú eras, que tú fuiste,

que tuviste nombre y casa,

y bulto, y país y oficio;

pero ahora eres nonada, no más que una 'aparecida",

$$
\text { ("Perdiz", 140). }
$$

El Poema de Chile se publicó, como ya he dicho, después de su muerte (y de mala manera, no me aburre repetirlo, de partida desconociendo el singular de su título, ya que quien lo editó lo tituló tontamente "Poemas de Chile"), y recién en los últimos años está siendo valorado como corresponde por algunos críticos jóvenes, como Soledad Falabella y Adrián Baeza. Se trata a mi juicio de una obra cumbre de la historia de la literatura chilena, ni más ni menos. Es el libro en que Mistral, incluso sin pretenderlo, pero muy a tono con el carácter de los tiempos, adopta un gesto propositivo, desplegando y magníficamente su deseo de país. Más todavía: eso lo hace ella de manera pedagógica, enseñándole al niño atacameño que camina

13. Gabriela Mistral. "Jardines" en Poemas de Chile. Doris Dana, ed. Barcelona. Pomaire, 1967, p. 87. En las próximas citas Poema..., daré sólo el título y número de página entre paréntesis. 
a su lado y que es la encarnación del pueblo chileno del porvenir, las miserias y maravillas de la tierra chilena. Y, dentro de estas últimas, la pequeña propiedad (la "hectárea por cabeza de familia", esa que trabajan todos los de la casa y que reúne al atributo de una extensión razonable la utilidad y la hermosura), es una vez más la que concita su mayor aprecio. Tanto es así que se define a sí misma a partir de ella:

\author{
--Chiquito, yo fui huertera. \\ Ese amor me dio la mama. \\ Nos íbamos por el campo \\ por frutas o hierbas que sanan. \\ Yo le preguntaba andando \\ por árboles y por matas \\ y ella se los conocía \\ con virtudes y con mañas
}

$$
\text { ("Huerta", 52-53) }
$$

Por lo tanto, se entiende que yo considere un error craso leer el Poema de Chile como si éste fuera el resultado del patriotismo de Mistral o de su nostalgia por el paisaje chileno y nada más. Poco cuesta mostrar, en efecto, que, como en la mejor literatura regionalista latinoamericana de nuestra segunda modernidad (Rivera, Gallegos, Icaza, Lins do Rego), se combinan en este texto el despliegue de la naturaleza americana, chilena en el presente caso, con la denuncia social. Y una de las grandes avenidas de la denuncia social de Gabriela Mistral (la otra es la indigenista, también como en el mejor regionalismo latinoamericano ${ }^{14}$ ) es la que tiene que ver con el "reparto" de la tierra entre aquellos que la trabajan o, dicho con el lenguaje de los economistas y sociólogos, su toma de posición inequívoca a favor de la reforma agraria, que como hemos visto es de antigua data y obedece tanto a sus experiencias particulares de muchacha provinciana y de maestra rural como a lo que le tocó ver en México. En el Poema..., esta línea temática surge a medio camino de la peregrinación de la hablante y sus dos compañeros por el territorio patrio, en "Flores":

14. "Digo sin ningún reparo "remordimiento". Creo a pies juntillas en los pecados colectivos de los que somos tan responsables como de los otros, y es el dogma de la Comunión de los Santos el que me ha traído en su espalda el dogma mellizo. No valen, dice el primero, los méritos de los mejores, y se comunican desde el primero al último de nosotros como el ritmo de las manos en la ronda de los niños; nos manchan y nos llagan, creo yo, los delitos del matón rural que roba predios de indios, vapulea hombres y estupra mujeres sin defensa a un kilómetro de nuestros juzgados indiferentes y de nuestras iglesias consentidoras". "Música araucana” en Recados..., 86. 
--Cuando me pongo a cantar

y no canto recordando, sino que canto así, vuelta tan solo a lo venidero, yo veo los montes míos y respiro su ancho viento. Cuando es que el camino va lleno de niños parleros que pasan tarareando lo más viejo y lo más nuevo, con semblantes y con voces que los dicen placenteros, yo veo una tierra donde tienen huerto los huerteros. $Y$ cuando paro en umbrales de casas y oigo y entiendo que Juan Labrador ya se labra huerto suyo y duradero, a la garganta me vienen ganas de echarme a cantar tu canto y lo voy siguiendo

("Flores", 99)

Desde aquí se comunica a por lo menos cuatro textos más, a

"Manzanos":

--Mama, repite otra vez aquello, aquello que has dicho, que vamos a tener todos

sí, sí, huerta... o huertecillo.

Pero tanto tiempo dicen

eso mismo y no ha venido.

Cree ahora a quien lo dice:

la huerta viene en camino.

¿Camino?

Sí, ya se acerca.

Está llegando, mi niño.

$$
\text { (“Manzanos" 109-110); a }
$$




\section{"Campesinos":}

Todavía, todavía

esta queja doy al viento:

los que siembran, los que riegan,

los que hacen podas e injertos,

los que cortan y cargan

debajo de un sol de fuego

la sandía, seno rosa,

el melón que huele a cielo,

todavía, todavía

no tienen un "canto de suelo".

(“Campesinos" 171-172); a

"Reparto de tierra":

Yo te escribo estas estrofas

llevada por su alegría.

Mientras te hablo mira, mira, reparten tierras y huertas.

¡Oye los gritos, los "vivas",

el alboroto, la fiesta!

¿Te das cuenta? ¡Entiende, mira!

Es que reparten la tierra

a los Juanes, a los Pedros.

("Reparto de tierra" 173-174): y a

“Adónde es que tú me llevas?”

--Te voy llevando a lugar

donde al mirarte la cara

no te digan como nombre

lo de "indio pata rajada", sino que te den parcela 
muy medida y muy contada.

Porque al fin ya va llegando

para la gente que labra

la hora de recibir

con la diestra y con el alma.

(“¿Adónde es que tú me llevas?, 180).

Fernando Alegría cuenta que Mistral, en su último viaje a Chile, el de 1954, en el discurso que pronunció desde un balcón de La Moneda, felicitó al gobierno [y ese gobierno era el de Carlos Ibáñez del Campo: "el mismo presidente que, en un período anterior, al hacerse cargo de la presidencia, le suspendió el sueldo", acota Alegría] por haber realizado una reforma agraria que solo estaba en su imaginación"15. Sigue diciendo el autor de Genio y figura: "Se ruborizaron los ministros, el presidente sonrió confuso, las gentes se codeaban sin poder creer lo que oían"16. Obviamente, lo que esas personas estaban sospechando era que en el cerebro de la insigne poeta se había desatado un síndrome de demencia senil.

A Alegría semejante conjetura no lo convence por completo, por lo que deja la puerta abierta para que la verificación de su descargo de colega, de amigo y de biógrafo quede librada a la buena voluntad del lector. Yo recojo ahora ese guante y, después de releer los extractos que copié más arriba, preciso lo que escribí en mi libro de 1997 y confirmo que el Poema de Chile o, mejor dicho, el modo cómo el Poema de Chile aborda el tema de la reforma agraria resuelve el enigma. Como en "El Valle Central de Chile", su artículo de 1937, también en el Poema de Chile da Gabriela por hecho el "reparto" de tierra, pero no sin hacernos sentir, proféticamente, que eso es algo que ella afirma con la lucidez "otra" de la mujer poeta.

No es que Mistral no sepa que la reforma agraria chilena no se ha hecho, por lo tanto. La perspectiva profética que adopta para estos propósitos en el Poema de Chile, y que difiere de la perspectiva patriótica y/o nostálgica que suele atribuírsele, privilegia, y es legítimo que así lo haga, dar por sucedido lo que está aún por suceder. Que Gabriela haya prolongado este ánimo profético posteriormente, en sus negociaciones con el mundo real, como cuenta Alegría, se puede achacar al mismo prurito. Santiago Daydí Tolson rescata una frase que ella pronunció en Nueva York, poco antes de embarcarse con rumbo a Chile, y que es decidora por demás: "Iré

15. Fernando Alegría. Genio y figura de Gabriela Mistral. Buenos Aires. Universitaria de Buenos Aires, 1966, p. 90.

16. Ibid. 
-dijo entonces- caminando por la tierra de Chile como un fantasma llevado de la mano por un niño" ${ }^{17}$. Lo único que nosotros podemos concluir, después de haber leído con atención esta cita, es que durante su último reingreso en territorio chileno Gabriela Mistral decidió superponerle a la codicia inhumana del país de los patrones la utopía esperanzada del país de los poetas.

Podría dar otros ejemplos de este poetizar mirando hacia "lo venidero", pero no me parece necesario. Me interesa mucho más comprobar en este punto de mi exposición que a su paso por el valle de Elqui en el Poema de Chile la poeta no hace referencia al tema de la reforma agraria y que resulta claro que, a partir de lo que recuerda por una parte y de lo que mitifica por otra, en el valle del río Elqui el problema que esta reforma debiera resolver no existe. Es más: el poético Elqui que ella tiene en su cabeza es precisamente el llamado a aportar la solución y esta no es otra que la del huerto familiar, ese del cual en los días felices de la infancia ella y la mama iban a sacar "frutas o hierbas que sanan".

Gabriela Mistral murió el 10 de enero de 1957 y por consiguiente no alcanzó a ver la reforma agraria chilena "de macetero" que aguijoneado por la Alianza para el Progreso hizo Jorge Alessandri (ley 15.020), ni la todavía demasiado parcial de Eduardo Frei, ni la que impulsó, ahora sí “en serio", el presidente Salvador Allende. ¿Qué habría pensado ella de esta última? Yo tengo para mí que hubiese tenido diferencias, pero que al fin y al cabo no habría podido menos que aprobarla, que no habría podido menos que aplaudir el que su profecía alucinada de los treinta, los cuarenta y los cincuenta se estuviese realizando por fin.

17. Santiago Daydí-Tolson. El último viaje de Gabriela Mistral. Santiago de Chile. Aconcagua, 1989, p. 124. Daydí toma la cita de un libro de Magdalena Spínola. Gabriela Mistral huéspeda de honor en su patria. Guatemala. Topografía Nacional, 1968, p. 32. 